\title{
La reestructuración productiva en el sector agrícola de Australia y Nueva Zelanda y su influencia en el sector lácteo
}

\section{Introducción}

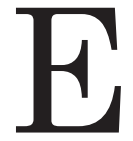
$n$ este artículo se presenta un panorama general de la industria lechera de Australia y Nueva Zelanda, entendiendo como industria a toda la cadena alimentaria que va de la producción a la comercialización de la leche. Se analizan algunas de las razones que hacen posible que el sistema de producción de leche en estas naciones sea uno de los más competitivos dentro de los países desarrollados. También se aborda la importante participación de estas economías en el mercado internacional de lácteos (que han liberalizado su sector agrícola), a pesar de estar muy regulado éste por parte de la mayoría de los países desarrollados. Finalmente, se habla de las reformas estructurales que se han realizado en este sector como parte de una estrategia general de liberación económica de ambos países en el contexto global.

* Profesor-investigador del Departamento de Estudios del Pacífico, CUCSH-Universidad de Guadalajara.

\section{Sistemas de producción de leche}

El caso de Australia

Australia se caracteriza por ser uno de los países más competitivos en la producción de leche a escala mundial; esta característica se debe principalmente a sus condiciones naturales que le permiten operar con costos de producción muy bajos. Las condiciones naturales son resultado de la gran calidad de pastos naturales que son utilizados como principal alimento del ganado, los cuales permiten reducir los costos y aumentar la cantidad de leche producida. La eficiencia en los costos de producción también es producto del desarrollo tecnológico, de las investigaciones llevadas a cabo para mejorar aún más la producción de pastos y del mejoramiento genético (Cf. Australian Dairy Corporation, 1990: 5).

Australia, junto con Nueva Zelanda, es un caso excepcional donde su sistema de producción de leche basado en el pastoreo le permite, dentro de los países desarrollados, obtener los costos de producción más bajos. Su competitividad se basa en mayor medida en sus ventajas comparativas y en menor medida en la intervención de las políticas gubernamentales. Por lo tanto, podemos decir que la competitividad se 
percibe como el resultado combinado de los efectos de las distorsiones de mercado (provocadas tanto por políticas como por la competencia imperfecta) y las ventajas comparativas (Velázquez, García y Martínez, 1998: 81).

Dentro de este esquema de producción general basado en el pastoreo, existen dos subsistemas de producción; uno de ellos se utiliza en dos terceras partes de las granjas lecheras en Australia y se conoce como sistema de producción estacional. En él se busca el apareamiento del ganado de tal suerte que logren tener sus crías y comenzar el periodo de lactancia en la estación del año cuando hay una abundancia de pastos naturales debido a las lluvias, lo que sucede normalmente durante la primavera principalmente en los estados de Victoria y Tasmania. En estos estados, a partir del mes de julio comienza a incrementarse la producción de leche hasta alcanzar su nivel más alto en el mes de octubre; después de éste comienza a descender hasta alcanzar el nivel más bajo en los meses de abril, mayo y junio.

El segundo subsistema de producción más importante en Australia es aquel que busca que el ganado tenga a sus crías durante todo el año, de tal suerte que la producción de leche se mantenga lo más estable posible. Este sistema se practica en las regiones donde es menor la variación estacional en la producción de pasturas, como en los estados de Nueva Gales del Sur, Queensland, el norte y el occidente de Australia (Meter y Puangsumalee, s/f).

\section{El caso de Nueva Zelanda}

De manera similar, aunque en mayor grado que Australia, Nueva Zelanda basa su sistema de producción de leche en el pastoreo. Éste es un sistema de producción poco común a escala internacional; en la actualidad se calcula que aproximadamente sólo $10 \%$ del ganado lechero en el mundo tiene como principal componente de alimentación el pasto; esta forma de explotación se encuentra en Nueva Zelanda, Australia y algunas zonas de Sudáfrica y Sudamérica (http://www.agritech.org.nz/ dairy.shtml, p. 2). A diferencia de los sistemas de producción estabulados, donde el ganado permanece gran parte del tiempo en los establos y su dieta se compone de forraje y granos, las condiciones naturales de Nueva Zelanda, que incluyen suelos con una abundante capa de materia orgánica, distribución excelente de lluvias y un invierno benigno, permiten evitar la estabulación invernal y contar con pastos durante todo el año sin necesidad de riego (FIRA, 2001: 38). Esta forma de explotación necesariamente requiere un espacio amplio para el ganado, y es así como está organizado. Actualmente en Nueva Zelanda existen aproximadamente 13,500 granjas lecheras y, en promedio, cada una cuenta con 250 bovinos y una extensión de 100 hectáreas, es decir 2.5 cabezas de ganado por hectárea.

Las características naturales mencionadas, además del desarrollo de innovaciones tecnológicas, han permitido que la producción de leche en Nueva Zelanda se realice con los costos de producción más bajos registrados en países desarrollados; sin embargo, es precisamente el sistema de producción basado en el pastoreo con bajo uso de granos, lo que también provoca rendimientos inferiores en la productividad hasta en $50 \%$ respecto a las granjas con manejo estabulado y uso de alimentos concentrados (FIRA, 2001: 40).

Como se puede observar en el cuadro anterior, mientras en Nueva Zelanda cada bovino produjo poco más de 3,500 litros de leche en promedio anual durante los últimos cuatro años, en Estados Unidos la 
La reestructuración productiva en el sector agrícola de Australia y Nueva Zelanda y su influencia en el sector lácteo

Cuadro 1

Promedio anual de producción de leche por vaca (litros)

\begin{tabular}{lccccc}
\hline País & 2000 & 2001 & 2002 & 2003 & 2004 \\
\hline Nueva Zelanda & 3,666 & 3,689 & 3,700 & 3,736 & 3,667 \\
Australia & 5,151 & 4,996 & 5,473 & 5,186 & 5,111 \\
Unión Europea* & 6,007 & 5,999 & 6,078 & 6,284 & n.d. \\
Estados Unidos & 8,254 & 8,235 & 8,438 & 8,504 & 8,636 \\
México & 1,369 & 1,393 & 1,245 & 1,375 & 1,437 \\
Mundo & 2,153 & 2,165 & 2,173 & 2,178 & 2,172 \\
\hline
\end{tabular}

n.d. = no disponible.

* Incluye a 15 países (Austria, Bélgica, Dinamarca, Finlandia, Francia, Alemania,

Grecia, Irlanda, Italia, Luxemburgo, Holanda, Portugal, España, Inglaterra y Suecia).

Fuente: www.fao.org

producción fue de más del doble, en Europa cercana al doble, y en Australia alrededor de $30 \%$ mayor que la que se registró en Nueva Zelanda. Como se mencionó antes, aunque los sistemas de producción entre Nueva Zelanda y Australia son parecidos, uno de los aspectos importantes que los distinguen es que en Nueva Zelanda su sistema se basa en mayor medida en el pastoreo, con mucho menos uso de suplementos alimenticios que en el sistema de producción australiano (Martin y Puangsumalee, s/f).

\section{Participación en el mercado internacional}

\section{El caso de Nueva Zelanda}

La razón por la que comienzo a analizar a Nueva Zelanda en lugar de Australia, que es el orden en el que venía anteriormente, es sólo por el hecho de que Nueva Zelanda tiene una mayor relevancia en el mercado internacional.

Comúnmente la mayoría de los países consumen casi el total de la leche que producen y sólo una parte marginal se destina al comercio internacional. Actualmente poco menos de 10\% de la producción mundial es lo que se comercia internacio- nalmente, excluyendo lo que se comercia entre los países de la Unión Europea ${ }^{1}$. Así, en 2003 el comercio internacional de lácteos en el mundo, incluyendo el comercio entre países de la Unión Europea, fue de 77,842 millones de litros, es decir 15\% de la producción mundial; en cambio, si descontamos el comercio realizado entre estos países, el comercio mundial de lácteos es de 44,303 millones de litros de leche, o 8.5\% del total mundial.

Nueva Zelanda es el único país en el mundo que exporta cerca de $80 \%$ de su producción interna de leche. Esta diferencia respecto a otras naciones se debe a que se ha desarrollado una industria lechera muy competitiva frente a un mercado interno que es relativamente pequeño, lo que lo convierte en el mayor exportador de lácteos del mundo. Si se analizan las exportaciones mundiales de leche, incluyendo el comercio que se registra entre países de la Unión Europea, a esta última región correspondería 58\% del comercio total, a Nueva Zelanda $14 \%$ y finalmente estaría Australia con casi 6\% de participación (2003); más aún si se excluye el comercio de lácteos al interior de la Unión Europea y sólo se contabilizan sus exportaciones fuera de la región, la participación de esta última en el comercio

MÉXICO YLACUENCADEL PACÍFICO vol. 9, núm. 27 / enero - diciembre de 2006 
Análisis

Cuadro 2

Comercio internacional de lácteos, exportaciones

\begin{tabular}{|c|c|c|c|c|c|c|c|c|}
\hline & \multicolumn{4}{|c|}{ El equivalente a millones de litros } & \multicolumn{4}{|c|}{ Millones de dólares de EUA } \\
\hline & 2002 & $\%$ & 2003 & $\%$ & 2002 & $\%$ & 2003 & $\%$ \\
\hline $\begin{array}{l}\text { Nueva } \\
\text { Zelanda }\end{array}$ & 11,034 & 14.97 & 11,352 & 14.58 & 2,592 & 9.70 & 2,932 & 9.00 \\
\hline Australia & 6,118 & 8.30 & 4,540 & 5.83 & 1,578 & 5.90 & 1,348 & 4.14 \\
\hline $\begin{array}{l}\text { Unión } \\
\text { Europea* }\end{array}$ & 40,846 & 55.41 & 45,911 & 58.98 & 18,042 & 67.50 & 23,333 & 71.60 \\
\hline $\begin{array}{l}\text { Estados } \\
\text { Unidos }\end{array}$ & 2,616 & 3.55 & 2,826 & 3.63 & 540 & 2.02 & 610 & 1.87 \\
\hline México & 105 & 0.14 & 109 & 0.14 & 44 & 0.16 & 47 & 0.14 \\
\hline Mundo & 73,712 & 100.00 & 77,842 & 100.00 & 26,730 & 100.00 & 32,590 & 100.00 \\
\hline
\end{tabular}

* Incluye el comercio intraeuropeo.

Fuente: http://www.fao.org.

mundial disminuiría a $27 \%$, la de Nueva Zelanda se incrementaría a $25 \%$, y la de Australia también se incrementaría a 10\%, es decir, Nueva Zelanda por sí sola estaría contribuyendo con un cuarto del total de exportaciones lácteas en el mundo.

\section{Principales mercados de exportación}

De acuerdo con información del Ministerio de Agricultura y Silvicultura del gobierno de Nueva Zelanda, en 2004 el principal mercado de exportación (44\%) fue la región de Asia, destacando los mercados de China, Filipinas, Japón y Malasia; en importancia le siguieron la Unión Europea con 13\%, Estados Unidos 12\%, el Medio Oriente 12\% y México 6\%. La participación que tiene Asia como principal destino de las exportaciones lácteas de Nueva Zelanda ha sido propiciada por una serie de factores como el creciente nivel de ingresos de la población en la región y los cambios en los patrones de consumo, así como por la búsqueda de diversificación de mercados que emprendió el gobierno de Nueva Zelanda a partir de 1972, año en que el Reino Unido, principal mercado de exportación, decidiera formar parte de la hoy conocida Unión Europea y con ello se vieran disminuidas las ventajas que este mercado proporcionaba. A finales de los sesenta a Nueva Zelanda no le quedó otro camino que buscar nuevos mercados de consumo, ya que sus exportaciones de lácteos hacia el Reino Unido concentraban 90\% de su producción (http://europa.eu.int/).

Entre los principales productos lácteos de exportación de Nueva Zelanda, la leche entera en polvo es la más importante, ya que representa más de $30 \%$ del valor

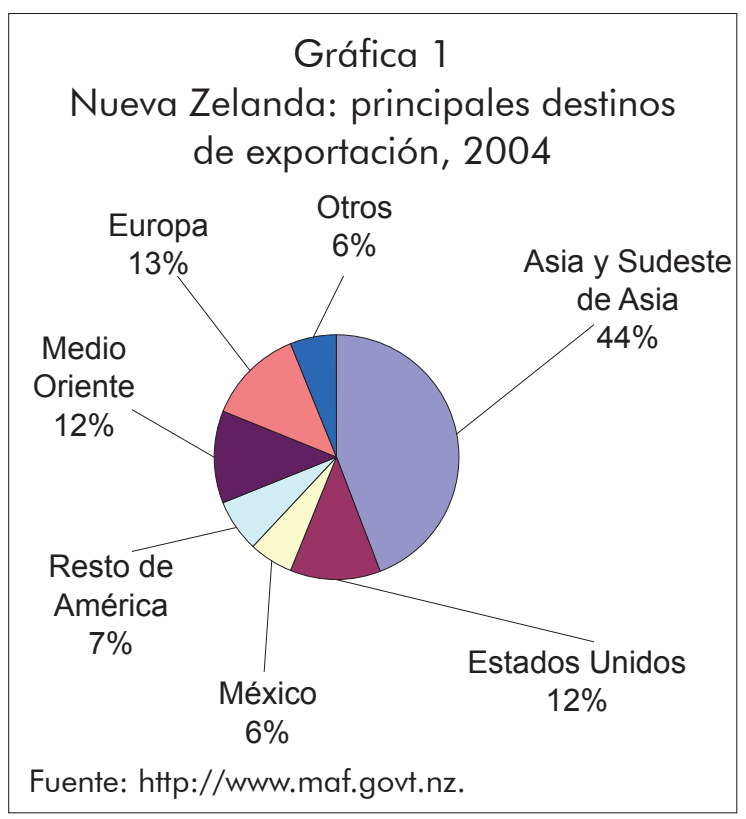


total de las exportaciones; le siguen la mantequilla con $18 \%$, el queso con $17 \%$ y finalmente la leche descremada en polvo y caseína, cada una con $14 \%$ del valor total de exportación en 2004. En su conjunto estos cinco productos representaron $95 \%$ del valor total de exportaciones en 2004 .

\section{Gráfica 2}

Nueva Zelanda: total de exportación de lácteos por producto, 2004

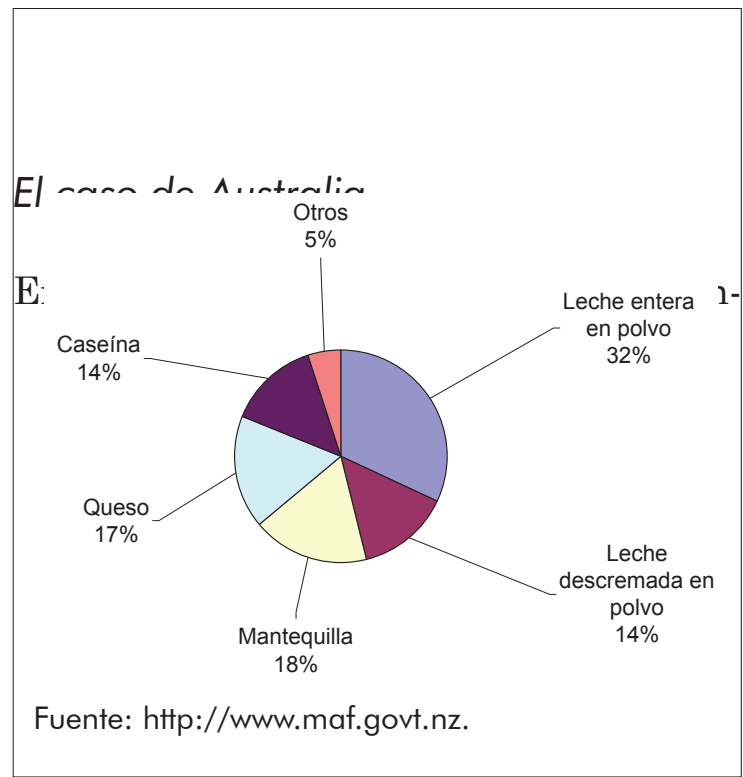

da, aunque en menor proporción, también en Australia la producción interna de leche supera la demanda interna. De este modo, Australia exporta cerca de $50 \%$ de la producción interna. Una fuente diferente de la de la FAO, como se muestra a continuación, nos dice que la Unión Europea continúa siendo el principal exportador mundial de lácteos con 34\% del total, seguido de Nueva Zelanda con $32 \%$ y Australia en el tercer puesto con $13 \%$.

Asimismo, de manera similar al caso de Nueva Zelanda, Australia concentra la mayor parte de sus exportaciones en el mercado de Asia, siendo Japón su principal mercado, el cual concentra $20 \%$ de sus

\section{Gráfica 3}

Principales exportadores de lácteos en el mundo, porcentaje de participación equivalente en leche, 2004

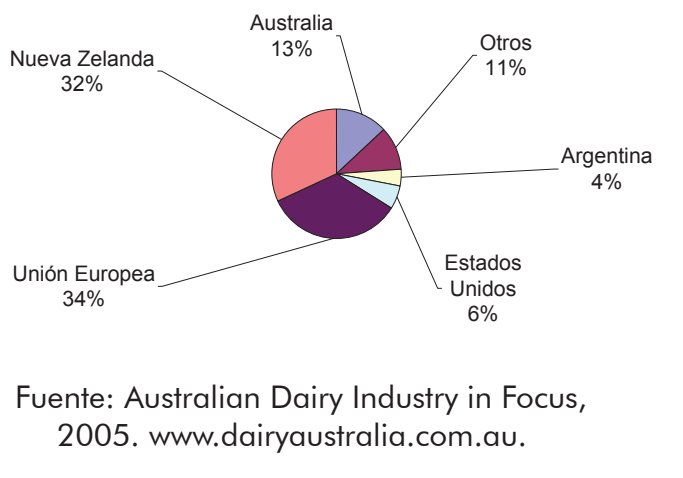

exportaciones totales. Australia, al igual que Nueva Zelanda, también tuvo graves problemas en su industria láctea a inicios de los setenta, en primer lugar porque en 1973 Gran Bretaña decidió formar parte de la Unión Europea y con ello terminaron las tarifas preferenciales para Australia; en segundo lugar, hubo una fuerte campaña en Australia y en los principales mercados de Europa, orientada al consumo de productos más sanos como el de la margarina en lugar de la mantequilla, lo que provocó que en 1972-1973 el mercado de la mantequilla, tanto interno como externo, disminuyera $24 \%$, seguido de una reducción de $41 \%$ al año siguiente; finalmente, como resultado de los excedentes lácteos acumulados en Europa y Estados Unidos, los precios internacionales de la leche disminuyeron. Lo anterior provocó que en Australia se diera una reducción en la producción de leche, una diversificación en la producción de lácteos y una búsqueda de nuevos mercados. Finalmente, a partir de los ochenta la industria se fue recuperando poco a poco, una vez que la producción mundial de leche disminuyera como consecuencia de una reducción en los 


\section{Análisis}

subsidios y de otros apoyos a la producción en países importantes de la Unión Europea y Estados Unidos (Australian Dairy Industry Council, 1996: 17 y 18).

\section{Gráfica 4}

Australia: principales destinos de exportación, 2004-2005

Entre los principales productos de exportación se encuentran el queso, la leche

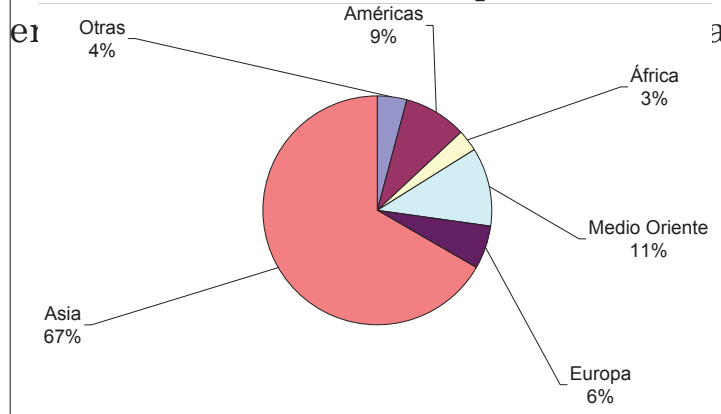

Australian Dairy Industry in Focus, 2005. www.dairyaustralia.com.au.

juntos estos tres productos representan poco más de $70 \%$ del valor total de sus exportaciones. La mantequilla, que era el principal producto producido y exportado (comparado con el queso y la leche en polvo) a inicios de los setenta, a partir de esa fecha su producción fue disminuyendo hasta alcanzar el nivel más bajo a inicios de los ochenta. Desde ese año la producción de este lácteo se ha ido recuperando pero su participación (tanto en la producción como en la exportación), comparada con la del queso y leche en polvo, ahora es mucho menor (Australian Dairy Industry in Focus, 2005; Australian Dairy Industry Council, 1996).

\section{Gráfica 5}

Australia: total de exportaciones de lácteos por producto, 2004-2005

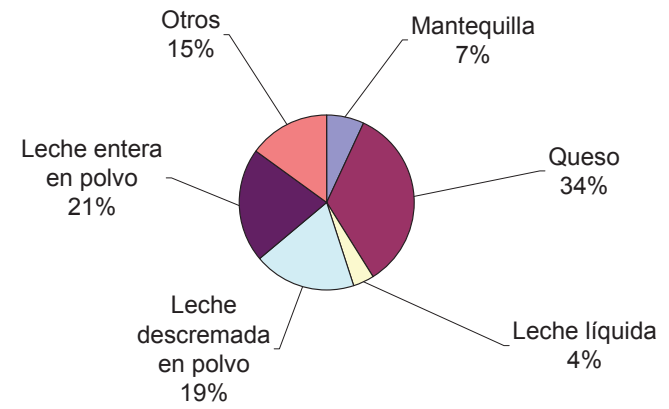

Fuente: Australian Dairy Industry in Focus, 2005. www.dairyaustralia.com.au.

\section{Apoyos al sector lácteo}

En la mayoría de los países desarrollados, con excepción de Australia y Nueva Zelanda, existen una gran variedad de mecanismos de apoyos a la producción agropecuaria (incluyen los de la leche). Tal es el caso de algunas de las economías más avanzadas, como las de Europa y Estados Unidos. Los apoyos son muy diversos, incluyen desde subsidios a la exportación y a los diferentes insumos para la producción, restricción a las importaciones, fijación de precios que garantizan la obtención de un beneficio positivo, etcétera. Australia, al igual que Nueva Zelanda, son países desarrollados que mantienen en la actualidad una política de apoyos muy bajos hacia el sector agrícola. El país que en menor proporción apoya al sector agropecuario es Nueva Zelanda. Sin embargo, Australia es el país que más se acerca en cuanto al comportamiento de sus políticas agrícolas. Así lo muestran las reformas que ha puesto en marcha en los últimos años el gobierno australiano, el cual se orienta hacia una política de menor intervención en el sector 
agropecuario (cf. Knudsen, Nash, Bovard, Gardner y Winters, 1993: 8).

Los subsidios agrícolas que son otorgados principalmente por países desarrollados provocan incrementos a la producción que finalmente se traducen en una baja en los precios a nivel internacional; esto hace más difícil que los países pobres puedan competir con sus productos primarios en un mercado altamente subsidiado. Aún más, debido a la baja en los precios internacionales de algunos productos primarios, muchos países subdesarrollados optan por incrementar sus importaciones de estos productos, lo cual provoca serios daños a su sector agropecuario interno. Para los casos de Nueva Zelanda y Australia, que son países desarrollados pero muy productivos en la producción de leche con fuerte presencia en los mercados internacionales, la baja en los precios de la leche provocados por los elevados subsidios que se destinan a la producción en otros países tienen una repercusión directa en el sector lácteo de estos países debido a que se reducen sus niveles de ingreso.

Entre los países desarrollados, Nueva Zelanda es el que otorga menos subsidios a su sector lácteo. Una forma de medir estos apoyos es a través de un indicador conocido como "estimación de la ayuda al productor", la PSE$^{2}$ (the Producer Support Estimate), antes conocido como el equivalente del subsidio al productor; este indicador es una medida adoptada por la OCDE para medir el grado de ayuda a la agricultura. En el caso de Nueva Zelanda, la PSE otorgada al productor de leche entre
2001 y 2003 se ha mantenido en $1 \%$ anual, que contrasta con el $9 \%$ en el periodo 1986-1988; sin embargo, en ese entonces era muy bajo respecto a las estimaciones de ayuda al productor que realizaban las demás economías desarrolladas. En 2003 la diferencia en la ayuda otorgada por los gobiernos al sector lácteo continúa siendo amplia. En Estados Unidos fue 45\%, en Japón 77\%, Canadá 59\%, Unión Europea $51 \%$, México 33\%, Corea del Sur 68\% y Australia 15\% (OCDE, 2004).

Otro indicador que utiliza la OCDE (Organización para la Cooperación y el Desarrollo Económico) para evaluar la ayuda otorgada a productores agropecuarios se conoce como el coeficiente de protección nominal (NPC, siglas en inglés), el cual se emplea para evaluar el nivel de protección resultante de distorsiones de mercado. Lo que se mide con éste es la relación entre el precio interno que reciben los productores por su producto y el precio en el mercado internacional de ese producto. En México por ejemplo, para el caso de la leche este indicador fue de 1.46 en 2003, esto reflejaba que en ese año el precio promedio que recibieron los productores de leche en México fue 3.22 pesos por litro; sin embargo, en el mercado internacional el precio era de 2.20 pesos el litro, lo que significaba que había una ayuda implícita a los productores de leche en México de 46\%. En Estados Unidos el indicador fue 1.76, en Corea del Sur 3.00, en la Unión Europea 1.98, Canadá 2.31, Japón 4.19 y en Nueva Zelanda y Australia fue 1.00, lo cual indica que en estos países no hubo 
ayuda implícita, o que el precio que recibieron los productores de leche fue igual al internacional.

Es importante aclarar que este indicador, el NPC, forma parte de lo que se conoce como el "apoyo al precio de mercado" (Market Price Support, MPS) y es uno de los componentes que tiene una proporción de aproximadamente dos tercios dentro de la PSE, es decir más de 60\% del valor de la PSE se calcula con la diferencia entre los precios internos de los productos agropecuarios y los precios internacionales (http://www. oecd.org/dataoecd/63/8/32035391.pdf, p. 4). Sin embargo, si se considera que son precisamente los apoyos que reciben los productores agrícolas en países desarrollados los que principalmente provocan incrementos en la producción y la oferta mundial, y por tanto una disminución en el precio internacional, resulta cuestionable el tamaño de la ayuda implícita que resalta en países desarrollados el cálculo de este indicador. De esta forma, probablemente si no hubiera subsidios tan elevados la producción mundial se reduciría, el precio aumentaría y la diferencia entre los precios en frontera y los internos serían quizás menores, con lo que tanto la PSE como el NPC para el caso de México y otros países serían menores.

\section{Reforma estructural}

\section{El caso de Australia}

Australia, al igual que la mayoría de los países, ha realizado cambios en su política económica interna en las últimas dos décadas. Estos cambios están enfocados en reducir las intervenciones del gobierno y permitir que las actividades económicas se orienten únicamente por las señales del mercado.

De acuerdo con esta nueva realidad, en los años noventa Australia promovió un paquete de políticas orientadas a incrementar los beneficios de los trabajadores del campo y mejorar la competitividad en el ámbito internacional (http://www.dpie.gov. au, septiembre 1997, p. 3). En general los apoyos proporcionados al sector rural antes de 1982 no fueron uniformes. Los más altos niveles de protección fueron dirigidos a la irrigación de cosechas, al sector lácteo, al de azúcar y al de huevo, mientras que otras actividades que eran consideradas más eficientes como las de la lana y la carne de vaca se mantuvieron sin intervención o con un nivel de apoyo relativamente bajo (ibídem, pp. 6 y 7).

La transición que se dio en Australia entre 1982 y 1992 estuvo orientada a responder a las señales del mercado y a la eliminación de las intervenciones del gobierno en forma gradual. Se lograron acuerdos entre el gobierno, la industria y el sector laboral para establecer salarios por abajo de la inflación con el fin de reducir los costos del trabajo y estimular la inversión; al mismo tiempo, el gobierno promovió la desregulación de los mercados financieros con el fin de que estos recursos estuvieran disponibles con mayor rapidez para los individuos y sus negocios (ibídem, p. 7).

Con esta serie de reformas la agricultura fue tratada como parte integral de la economía, sin ninguna consideración especial. Las medidas se orientaron a reducir los niveles de protección comerciales sobre las importaciones, con el fin de ir reduciendo en forma gradual las barreras al comercio.

En 1995 una gran cantidad de productos quedó libre de restricción; únicamente permanecieron con protección algunas industrias agrícolas como las de los cítricos, la leche, el azúcar, las frutas y otras, en las que la reducción en la protección ha sido en forma gradual (ibídem, pp. 9 y 10). El apoyo al sector lácteo y la desregulación 
paulatina se debieron a que normalmente este sector ha sido uno de los más protegidos en muchos de los países desarrollados, lo cual provocaba y continúa provocando una competencia no equitativa.

\section{Reforma en la política de la industria de la leche}

Hasta principios de los ochenta en Australia existía un control centralizado en el mercado de las exportaciones. Además, debido a que la industria de la leche no era muy grande en términos relativos y estaba formada por pequeñas cooperativas, la obtención de información sobre los mercados de exportación era muy costosa.

Dado lo anterior, el sector procesador fue regulado conjuntamente mediante acuerdos de exportación entre las pequeñas cooperativas productoras de leche con precios asegurados; además de esto, el precio interno en Australia era controlado por la legislación de cada uno de los estados.

Antes del primero de julio de 2000 la regulación en la industria de la leche de Australia se dividía en dos partes: por un lado estaba el sector de leche líquida conocido como mercado de la leche (milk market), y por otro, el sector de leche industrializada (manufacturing milk). Ambos sectores fueron apoyados de manera distinta. El mercado de leche líquida fue apoyado de manera independiente en cada uno de los estados de Australia, y el sector de leche industrializada consistió en un esquema de asistencia federal por la Commonwealth.

Los controles de los gobiernos estatales sobre el precio y la oferta de la leche líquida, conocido como mercado de leche, habían estado presentes por lo menos desde 1980 en la mayoría de los estados, y en otros desde algunos años más. El precio que el estado garantizaba por la producción de cierta cantidad de leche líquida estaba muy por encima del precio promedio que se pagaba por el resto de la oferta de leche no regulada, ${ }^{3}$ a pesar de que no existían diferencias en el producto. De acuerdo con la política de desreglar el mercado, las cuotas y los precios de control estatal finalizaron el primero de julio de 2000; esto significa que ya no existen controles sobre la cantidad o el precio de la leche producida, y por lo tanto existe un mercado libre en las ventas de leche líquida en Australia (http:// www.aph.gov.au/library/pubs/bd/2000-01 /01bd167.htm).

En lo que concierne al apoyo por parte del gobierno de la Commonwealth, dos eran los programas más importantes que ofrecían asistencia al sector. Los programas se conocieron como el Plan Kerin y el Plan Crean de 1986 y 1992, respectivamente.

La estrategia del Plan Kerin de 1986 se basaba en una política que mantenía los precios internos de los productos lácteos por arriba de los precios de exportación (aproximadamente dos centavos por litro); esto estaba ligado a un pago que se efectuaba a aquellas exportaciones de productos lácteos que, a su vez, dicho dinero utilizado para estos fines provenía de un impuesto que se aplicaba a toda la producción de leche en Australia. Esta estrategia, que estimulaba el incremento de los precios internos de los lácteos, finalmente se traducía en un beneficio neto hacia los productores de leche, ya que se incrementaba el precio de la leche que era utilizada para la elaboración de productos lácteos destinados para consumo interno (http:www.dairy. com.au./adc/profile/markarr, mayo 1997, p. 1). El Plan Crean de 1992 sustituyó al anterior, y lo que planteó básicamente fue ir reduciendo los apoyos gradualmente hasta eliminarlos en junio 30 de 2000.

A partir de 1995 los apoyos tuvieron que ser rediseñados debido a que de 
acuerdo con la OMC el esquema de pagos para apoyar la exportación de productos lácteos constituía un subsidio a las exportaciones.

El nuevo esquema fue administrado por la Corporación Australiana de Leche (Australian Dairy Corporation, ADC); asimismo, las medidas fueron derivadas de los planes Kerin y Creen que, como se mencionó, fueron introducidos en 1986 y 1992 respectivamente. A partir de julio de 1995 se estableció esta nueva estrategia política con el propósito de cumplir con los acuerdos que Australia había contraído en el marco de la Ronda de Uruguay. Para esto, el nuevo plan trató de que los industriales de la leche mantuvieran los mismos beneficios que con el plan anterior. El cambio fundamental respecto a los planes anteriores consistía básicamente en que el apoyo interno se realizara de tal manera que no se interpretara como un subsidio a las exportaciones. Finalmente, la modificación quedó de la siguiente manera: los productores de leche pagaban un impuesto por la leche que vendían internamente para consumo directo (alrededor de dos centavos por litro); a su vez, los industriales de la leche pagaban un impuesto (en 1996-1997 el pago fue de alrededor de cuatro centavos por litro) por los productos lácteos que se vendían internamente. La leche utilizada para la elaboración de lácteos destinados a la exportación quedó exenta de impuestos. En este sentido, los apoyos a las exportaciones bajo esta lógica terminaron en junio 30 de 2000. Finalmente, los recursos de los impuestos que habían sido obtenidos mediante estas nuevas medidas fueron utilizados para realizar pagos a aquellos productores cuya leche era destinada a la elaboración de productos lácteos (ibídem, p. 2; http://www.dairy.com.au/adc/profile/ dairystr, mayo 1997, p. 2) y los criterios para realizar dichos pagos se establecieron en función de la calidad y la cantidad de leche ofrecida.

De 1986 a 1996 la ayuda a la industria de leche había declinado aproximadamente en $65 \%$ y se esperaba fuera eliminada completamente, en forma gradual, para el año 2000. No obstante la reducción de los apoyos por parte del gobierno desde 1986, una década después, la producción de leche se había incrementado en una tercera parte y el volumen de las exportaciones había aumentado al doble, ello a pesar de que hubo una reducción de $10 \%$ en el número de cabezas de ganado y una disminución de $30 \%$ de las granjas lecheras (http://www. dpie.gov.au/dpie/agriculture/agricultural_reform.html, mayo 1997, p. 12).

Para aminorar los efectos de la desregulación en el sector de la industria de leche el gobierno de la Commonwealth introdujo una nueva legislación que comenzó a aplicarse el primero de julio del año 2000. A esta nueva ley se le conoce como Paquete de Ajustes a la Industria de la Leche (Dairy Industry Adjustment Package, DIAP), que contiene tres programas (ABARE, 2001: 4 y 5). El primero consiste en financiar mediante pagos trimestrales durante los próximos ocho años a partir del 2000, a todos aquellos granjeros que estuvieran interesados en continuar con la producción de leche. Para realizar estos pagos se tomaron como referencia los volúmenes de producción de leche líquida e industrializada durante los años 1998 y 1999.

El segundo programa consistió en apoyar con 45,000 dólares australianos (equivalentes a 25,875 dólares estadounidenses) libres de impuestos, para aquellos granjeros que desearan abandonar la actividad. El tercer programa tuvo como finalidad destinar recursos a las comunidades dependientes del sector lechero que fueron afectadas por los programas de desregulación. 
El caso de Nueva Zelanda

Después de la Segunda Guerra Mundial Nueva Zelanda adoptó una fuerte política proteccionista, la cual se intensificó a finales de los setenta y principios de los ochenta en un intento por conservar la prosperidad de los años cincuenta (Evans, 2004: 4). Sin embargo, a partir de 1984, al igual que en muchos otros países en la década de los ochenta, esta nación comenzó un programa importante de liberalización económica. Los cambios en la economía de Nueva Zelanda durante los ochenta se caracterizaron por su amplitud, la consistencia de las reformas y el bajo nivel de liberalización por el que comenzaron. Muchos programas de la agricultura cambiaron dramáticamente: los esquemas de apoyo al precio fueron eliminados, se terminaron los préstamos para el desarrollo de las granjas y el subsidio a fertilizantes; además, la función del Banco Rural fue reorientada poco a poco hacia la comercialización de sus actividades, ello provocó el incremento en las tasas de interés que, aunado a la caída del ingreso agrícola, condujo a una crisis de endeudamiento rural (www.ifama.org/, p. 4).

\section{Reforma en la política de la industria de la leche}

La liberalización en la economía de Nueva Zelanda implicó cambios en el sector agropecuario en general y en el sector lácteo en particular. Estos cambios propiciaron una mayor concentración de la producción de leche; por ejemplo, a mediados de los ochenta el número de compañías lecheras (principalmente cooperativas) que existían en Nueva Zelanda eran 30, mientras que para 1998 quedaban solamente ocho. Este proceso condujo finalmente a una de las fusiones más grandes en 2001, en la que las dos principales cooperativas lecheras de Nueva Zelanda (New Zealand Dairy Group y Kiwi Dairies) y la Compañía Lechera de Nueva Zelanda (New Zealand Dairy Board, NZDB) acordaron formar una cooperativa conocida formalmente como Compañía Lechera Global (Global Dairy Company), ahora conocida como Grupo Cooperativo Fonterra (Fonterra Cooperative Group). Fonterra es actualmente la cooperativa más grande de Nueva Zelanda ya que recibe y procesa alrededor de $95 \%$ de la leche producida en el país.

El antecedente más lejano de Fonterra inicia en 1923 con la creación del Consejo para el Control de la Exportación de Productos Lácteos (Dairy Produce Export Control Board), el cual fue creado por iniciativa del gobierno con el fin de controlar todas las exportaciones de lácteos bajo el argumento de que las compañías procesadoras eran demasiado pequeñas para que por su propia cuenta pudieran exportar eficientemente. Posteriormente este consejo sería conocido como the New Zealand Dairy Board (NZDB), el cual en 1961 adquirió legalmente el estatus de exportador único. Dicho estatus creaba serios problemas de libre competencia debido a que, como el mercado de Nueva Zelanda era y continúa siendo demasiado pequeño, cualquiera que se iniciara en este negocio tendría que exportar sus productos con el fin de ampliarse; sin embargo, para hacerlo se debía solicitar autorización a sus competidores, quienes eran propietarios de la compañía exportadora y por lo tanto ello implicaba una clara desventaja en términos de competencia. Entre otros factores, éste era uno de los puntos más cuestionados de la política gubernamental, por lo que finalmente se logró impulsar un cambio estructural con el fin de eliminar esta condición de exportador único (Evans, 2004: 8). Con la Ley de Reestructuración de

MÉXICO YLACUENCADEL PACÍFICO vol. 9, núm. 27 / enero-diciembre de 2006 
la Industria de la Leche en 2001 el estatus de exportador único que mantenía la NZDB quedó eliminado; asimismo, se autorizó la fusión entre la NZDB y las dos cooperativas más grandes del país para dar origen a Fonterra; con ello, la responsabilidad de comercializar los lácteos en el mercado internacional, que otrora tenía la NZDB, pasó, al menos de manera temporal, a ser una responsabilidad de Fonterra.

Con la reestructuración y la creación del Fonterra se logró poner fin al monopolio de exportación de productos lácteos; con esta ley, aunque la empresa conserva su función de principal exportador debido a su experiencia y al volumen de leche que acopia y procesa, legalmente perdió su condición monopólica; sin embargo, de acuerdo con la ley la empresa mantendrá por el momento licencias exclusivas de exportación a determinados mercados restringidos (http://www.wto.org/english/ tratop_e/tpr_e/s115-4_e.doc), que estarán vigentes en algunos casos hasta $2007 \mathrm{y}$ en otros hasta $2010 .{ }^{4}$

Por último, de acuerdo con datos de la propia empresa, Fonterra es actualmente la compañía más grande de Nueva Zelanda; es propiedad, bajo la modalidad de cooperativa, de más de 12 mil ganaderos; sus exportaciones representan más de $20 \%$ del total realizadas por el país y participa con $7 \%$ del producto interno bruto. Es además la empresa privada de Nueva Zelanda que más invierte en investigación y desarrollo, con un gasto anual aproximado de 95 millones de dólares neozelandeses, además de tres millones adicionales que recibe del gobierno vía la Fundación para la Investigación, la Ciencia y la Tecnología (Foundation for Research, Science and Technology) (http:www.fonterra.com).

\section{Conclusión}

Los procesos de apertura comercial y desregulación económica que se han dado en Australia y Nueva Zelanda, en particular en la industria de la leche, no han mermado en el largo plazo la cantidad de leche producida, la importante presencia de ambos países en el mercado internacional de lácteos, ni el incremento en la productividad de la industria. Esto se debe a varias razones. En primer lugar, ambas economías han aprovechando sus condiciones naturales y han desarrollado a lo largo de la historia un sistema de explotación lechera basado en el pastoreo, el cual resulta muy eficiente en términos de costos de producción. En segundo lugar, se han llevado a cabo una serie de políticas encaminadas a reestructurar la industria en términos de las nuevas exigencias que se han presentado tanto en el mercado internacional de lácteos como al interior de sus economías.

\section{Notas}

1. Se toman en cuenta los 15 países que formaban la Unión Europea hasta 2003 (Austria, Bélgica, Dinamarca, Finlandia, Francia, Alemania, Grecia, Irlanda, Italia, Luxemburgo, Holanda, Portugal, España, Inglaterra y Suecia); a partir de 2004 se adhirieron 10 más.

2. La "estimación de ayuda al productor" es un indicador del valor de las transferencias monetarias a la agricultura que resultan de las políticas agrícolas en un año dado.

3. En la década de los noventa, el precio más bajo de la leche fluida controlada fue de 48 centavos australianos y el más alto de 55 centavos. En el mismo periodo el precio promedio de la leche no controlada fue de entre 20 y 28 centavos en promedio.

4. Fonterra se beneficiará de licencias exclusivas de exportación hasta el 30 de junio de 2007 para las exportaciones al mercado de la República Dominicana, hasta el 31 de julio de 2007 para las exportaciones a determinados mercados de Canadá, hasta el 31 de diciembre de 2007 para 
las exportaciones a determinados mercados de la Comunidad Europea, hasta el 31 de diciembre de 2008 y 31 de diciembre de 2009 para las exportaciones de determinados quesos al mercado de Estados Unidos, y finalmente, tendrá licencia exclusiva hasta el 31 de marzo de 2010 para las

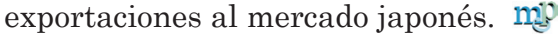

\section{Referencias bibliográficas}

Australian Dairy Corporation (1990) Annual Report, 1989-1990, Australia.

Australian Dairy Industry Council (1996) The comprehensive reference to the Australian Dairy Industry. Australia: Morescope Publishing Pty Ltd.

Evans, Lewis (2004) Structural reform: the dairy industry in New Zealand, APEC High Level Conference on Structural Reform, 8-9 de septiembre, Tokio.

Fideicomisos Instituidos en Relación con la Agricultura (FIRA) (2001) Boletín informativo, núm. 317, vol. XXXIII, p. 38. http://www.siap.sagarpa.gob.mx.

Knudsen, Odin, John Nash, James Bovard, Bruce Gardner, y L. Alan Winters (1993) "Redefining the role of government in agriculture for the 1990s", World
Bank Discussion Papers, núm. 105, $2^{a}$ edición, agosto, Washingtong, DC.

Meter, Martin, y Phantipa Puangsumalee (s/f) Farm performance in the Australian and New Zealand dairy industries. Australia: Australian Bureau of Agricultural and Resource Economics. www.abareconomics.com.

Muñoz Rodríguez, Manrubio, y Pius Odermatt (1991) El sistema lecèe de México en el marco del Tratado Trilateral de Libre Comercio, noviembre. México: Universidad Autónoma de Chapingo.

Organización para el Crecimiento y el Desarrollo Económico (OCDE) (2004) Agricultural policies in OECD countries at a glance.

The Australian Bureau of Agricultural and Resource Economics (ABARE) (2001) The Australian Dairy Industry, Impact of an open market in fluid milk supply, enero, Report to the Federal Minister for Agriculture, Fisheries and Forestry, Australia.

Velázquez, Víctor Manuel, Roberto García M., y Miguel Martínez D. (1998) "Análisis comparativo de los costos de producción de leche de vaca en siete países", Políticas Agrícolas, vol. III, núm. 3.

www.ifama.org/ (s/f) Changes in risk perception and risk management strategies in New Zealand dairy farming. 